\title{
Arbitrabilidad, inversión e ilegalidad
}

\author{
Mónica Jiménez \\ Andrea Saldarringa'
}

\section{SUMARIO}

1. Introducción. 2. La noción de Arbitrabilidad. 2.1. Arbitraje comercial internacional. 2.2. Arbitraje de inversión. 3. Arbitrabilidad e ilegalidad. 3.1. Arbitraje comercial internacional. 3.2. Arbitraje de inversión. 4. Conclusión.

\section{INTRODUCCIÓN}

Como punto de partida, es preciso reconocer que, si bien el concepto de arbitrabilidad resulta familiar a la práctica del arbitraje internacional, su uso suele circunscribirse al arbitraje comercial internacional siendo infrecuente -por no decir inexistente- en el arbitraje de inversión. ${ }^{2}$

Teniendo en cuenta esta circunstancia, el presente artículo se propone explorar la acepción y utilización del concepto de arbitrabilidad en el marco del arbitraje de inversión vinculándo-

1. Mónica Jiménez es asociada de la firma Fasken Martineau en Vancouver, Canadá y se especializa en temas de arbitraje internacional. Andrea Saldarriaga se desempeña como consultora en materia de arbitraje internacional y derecho internacional de las inversiones para la firma Gómez Pinzón Zuleta, desde Londres. Las autoras agradecen la valiosa colaboración de Scbastiản Mantilla, asociado de Gómez Pinzón Zuleta, en la preparación de este articulo.

2. Para los efectos de este articulo, la expresion 'arbitraje de inversión' se refiere especificamente al arbitraje que tiene como fundamento un tratado de inversión en el que el Estado manifiesta de forma unilateral su consentimiento para resolver mediante arbitraje las disputas relativas a la inversión. A su vez, la expresión tratado de inversión incluye tanto los tratados bilatcrales de inversión (en adelante, TBI) como los capitulos de inversión en tratados de libre comercio. 
lo, en particular, con la problemática que presenta el tratamiento de cuestiones de ilegalidad de la inversión, asunto que, con inusitada frecuencia, se viene presentando recientemente en este campo.

Con tal fin, el artículo comienza analizando la noción de arbitrabilidad en el arbitraje comercial internacional, para luego discutir su significado para el arbitraje de inversión. Seguidamente, se plantea la problemática relacionada con las cuestiones de ilegalidad para estudiar, posteriormente, la posible utilidad de la noción de arbitrabilidad en este contexto.

\section{LA NOCIÓN DE ARBITRABILIDAD}

\subsection{Arbitraje comercial internacional}

En el arbitraje comercial internacional, el vocablo 'arbitrabilidad' hace referencia a dos fenómenos diferentes. De un lado, está la llamada arbitrabilidad objetiva o ratione materine que se refiere a si la disputa es susceptible de ser sometida a arbitraje. ${ }^{3}$ Del otro lado, la arbitrabilidad subjetiva o ratione personae hace referencia a la posibilidad de las partes para someter sus disputas a arbitraje en razón de sus condiciones particulares. ${ }^{4}$ Para los fines de este artículo, se recurrirá a la noción de arbitrabilidad objetiva.

3. La arbitrabilidad objetiva tambićn se conoce como la doctrina de la inarbitrabilidad (non-arbitrability doctrine). Vease: BORN, Gary. International Commercial Arbitration. Wolters Kluwer, 2009, pp. 766-772.

4. Es comun que el argumento de la arbitrabilidad ratione personae sea invocado en disputas que involucran al Estado o a entidades estatales, donde la normatividad local restringe la capacidad del Estado a de dichas entidades para someter sus controversias a arbitraje. Vèasc, MISTELIS, Loukas A., "Part L. Fundamental Observations and Applicable Law. Chapter 1 - Arbitrability - International and Comparative Perspectives", en: MISTELIS, Loukas A. y BREKOULAKIS, Stavros L. (Eds), Arbitrability: International and Comparutise Perspectives, Kluwer Law International, 2009, págs. I18; GAILLARD, Emmanuel y SAVAGE, John (Eds.). Fotichard Gaillarl Goldman on International Commercial Arbitration. Kluwer Law International, 1999, pp. 312-313. 
En términos generales, el concepto de arbitrabilidad objetiva o ratione materine en el arbitraje comercial internacional se refiere a la posibilidad de que el asunto objeto de la controversia sea susceptible de ser sometido a arbitraje: de ser posible arbitrar la disputa, ésta podrá ser llevada ante los tribunales arbitrales; en caso contrario, estará sujeta a la jurisdicción exclusiva de las cortes nacionales. ${ }^{5}$ La posibilidad de someter una disputa a arbitraje no se confunde con la validez del pacto arbitral: a pesar de que éste se suscriba válidamente, una disputa cubierta por dicho acuerdo puede no ser arbitrable. Las cuestiones de arbitrabilidad pueden constituir una causal de anulación del laudo, o conducir a que el pacto arbitral sea inaplicable o a que el laudo resultante no sea ejecutable. ${ }^{6}$

La determinación de las materias que pueden ser arbitradas generalmente depende de una de las leyes relevantes para el arbitraje. De hecho, las diferencias en dicha calificación son el resultado de diversas tendencias jurídicas, reflejadas en las dis-

5. El concepto de arbitrabilidad ha sido también utilizado para determinar si una disputa es arbitrable por encontrarse dentro del ámbito de aplicación de la cláusula de arbitraje. En este contexto, la discusión se torna más especifica pues busca establecer si una disputa particular se encuentra bajo la jurisdicción de una corte. En este articulo no se recurrirá a este sentido restringido de 'arbitrabilidad', sino a su significado amplio (esto es, si la materia es susceptible de ser sometida a arbitraje en genemal). Sobre cste punto, véase: BLACKABY, Nigel y PARTASIDES, Constantine, Redfern and Hunter on International Arbitration, Oxford University Press, 2009, p. 123.

6. Tanto la Convención de Nueva York de 1958 sobre el Reconocimiento y la Ejecución de las Sentencias Arbitrales Extranjeras (en adelante 'Convenciún de Nueva York' o 'CNY') y la Ley Modelo de la Comisión de las Naciones Unidas para el derecho mercantil internacional (en adelante 'Ley Modelo CNUDMI), incluyen como causales para la denegación del reconocimiento y ejecución de un laudo que el objeto de la controversia no sea susceptible de ser resuelto por medio de arbitraje, Asi, el articulo II.I de la CNY establece: "... [cjada tuo de los Estades Contratantes reconocerá el acucrulo por escrito conforme al cual las partes se obliguen a someter a arbitraje todas las diferencias o ciertas diferencias gne hayan surgido o puedan surgir enure ellas respecto a una determinada relación juridica, contractual o no contrachul, concerniente a un asunto que pueda ser resuelto por arbitraje" En su articulo V.2.a, la CNY dispone: "[t]ambién se podra denegar el reconocimiento y la cjecucion de una sentencia arbitral si la autoridad competente del pais en que se pide el reconocimiento y la cjecuciỏn, comprucha: a) Quc, seguin la ley de ese pais, cl objeto de la diferencia no es susceptible de soluciün por via de arbitraje...". Convención de Nueva York sobre el Reconocimiento y Ejecución de las Sentencias Arbitrales Extranjeras. 1958, arts. Il.1 \& V.2.a. Por su parte, la Ley Modelo CNUDMI dispone en su articulo 36: "Motivos para denegar el recono. cimicnto o la ejecución: 1) Sólo se podrú denegar el reconocimiento o la cjecución de un laudo arbitral, cualquicra que sea el pais en que se haya dictado: b) cuando el tribunal compriebe: i) que. segrin la ley de este Estado, el objeto de la controversia no es susceptible de arbitraje; o ii) que el lauts es contrario al orden puiblico de esse Estado...". CNUDMI, Ley Modelo de Arbitraje Comercial Internacional, 1985, art. 36. 
posiciones legales imperativas o en la noción de orden público acogida por cada jurisdicción. ${ }^{7}$ Por ejemplo, algunas legislaciones nacionales excluyen las disputas que involucran al Estado o a entidades estatales o las que se refieren a temas de orden públi$\mathrm{co}$, tales como los asuntos regulados por el derecho penal o la protección al consumidor. Otras legislaciones prefieren apelar al uso de criterios jurídicos adicionales para delimitar el concepto de arbitrabilidad incluyendo, por ejemplo, la condición de que las partes puedan disponer de los derechos objeto de la disputa o el carácter pecuniario de los mismos. ${ }^{8}$

Estos límites surgen de la decisión de los gobiernos y cortes nacionales de excluir del arbitraje las materias que tienen un matiz o efecto público y que no deberían ser consideradas en un foro privado, como lo es el arbitraje. La tendencia actual parecería orientarse hacia una concepción restringida de los límites de la arbitrabilidad, de tal manera que pocas materias se encontrarían al final excluidas del arbitraje. ${ }^{9}$ Asimismo, la interpretación y uso de leyes domésticas en el contexto del arbitraje internacional dependerá de la naturaleza de la disputa. En esta medida, mate-

7. Es importante señalar que el conecpto de arbitrabilidad difiere del de orden público que constituye una causal independiente para, de un lado, ta denegación del reconocimiento y cjecución del laudo y, del otro, su anulación. Sin embargo, cstos conceptos tienden a sobreponerse y algunos autores consideran que las cuestiones de orden público subyacen o fundamentan las limitaciones impuestas por la noción de arbitrabilidad. Al respecto señala el autor Loukas Mistelis: "[a] pesar de la notable expansión del ambito de la arbitrabilidad en las viltimas dos décadas. la perspectiva prevalente es ain que consideraciones de orden publico subyucen la inarbitrabilidad". Este autor propone abordar el tema desde una perspectiva diferente, desligando has cuestiones de arbitrabilidad de las de orden público; en efecto, afirma: "en los limitados tipos de disputas que atin se consideran inarbitrables, la inarbitrabilidad se relaciona con las limitaciones naturales del arbitraje como un mecanismo de resolucioin de disputas de carácter consensual, meis que con el orden público. Este último. como se discute aqui, es efectivamente irrelevante para la discusión de arbitrabilidad". Traducción libre. MISTELIS, Loukas A., "Iart I. Fundamental Observations and Applicable Law. Chapter 1 - Arbitrability International and Comparative Perspectives", en: MISTISLIS, Loukas A. y BREKOULAKIS, Stavros L. (Eds), Arbitrability: International and Comparative Perspectives, Kluwer Law International, 2009. p. 19.

8. POUDRET, Jean-François y BESSON, Sèbasticn, Comparative Law of International Arbitration, 2nd ed., London: Swect \& Maxwell Led., 2007, p. 281.

9. En ese orden de ideas scĩala Gary Born que "... IJjos limites de inarbitrabilidad que existen bajo los derechos nacionales, ham evolucionado materialmeme en el ticmpo, con un escepticismo histórico acerca de la capacidad del proceso arbitral para resolver categorias particulares de disputas, que ha crosionado sustancialmente en décadas nécientes. Esta crosión ha progresado al pumto que ta mayoria de jurisdicciones desarrolladas imponen hoy sólo limites restringidos sobre los asuntos que pucten ser arbitrados". Traducción libre. BORN, Gary. International Commercial Arbitration. Wolters Kluwer, 2009, p. 775. 


\title{
rias que se considerarían no arbitrables bajo una ley doméstica particular, podrían llegar a serlo en un contexto internacional. ${ }^{10}$
}

\author{
La utilidad del concepto de arbitrabilidad en el arbitraje \\ comercial internacional se explica por la importancia de evitar el \\ arbitraje relativo a algunos temas que, ya sea por razones de \\ política pública o por voluntad del legislador, no deben estar
}

10. En ese sentido, se ha dicho que "el hecho de que un asunto particular no sca arbitrable en un escenario doméstico, bajo un derecho nacional particular; no necesariamente significa que no sera arbitrable en un escenario internacional: por el contrario, las reglas locales de inarbitrabilidad se interprefan frecuentemente como aplicables sólo a asuntos domésticos. La justificaciän de esta conclusion ha sido que, en casos internacionales, las concepciones nacionales de onten priblico y las leyes imperativas deben moderurse, a la ha de la existencia de intenes publicos de otros Estados enfrentados y la politica priblica internacional de fomentar la resolución de disputas conerciales internacionales mediante arbitraje". Traducción libre. BORN, Gary. International Commercial Arbitration. Wolters KJuwer, 2009, págs.775-776. Véasc también: BLACKABY, Nigel y PARTASIDES, Constantinc, Redfern and Hunter on Interitational Arbiration, Oxford University Press, 2009, pár. 2.114.

Al respecto resulta interesante la discusión en tomo a los coneptos de orden público nacional c internacional surgida como resultado de los desarrollos jurisprudencialcs de las cortes francesas que han debido ocuparse del tema, dado que el numeral 5 del articulo 1502 del Nuevo Código de Procedimiento Civil permitió denegar el reconocimiento y cjecución de un laudo cuando éste sca contrario al orden público intemacional. Al analizar dicha disposición, la Corte de Apelaciones de Paris anotó que "una violación del orden público doméstico-asumiendo que hay a sido establecida - no prove los fundancentos para apelar sua decision oforgando la cjecucion de in laudo arbitral extranjern en Francia, porque el articuio $15025^{\circ}$ sólo se refiere a los casos en que el reconocimientes o ejecución de un laudo serian contrarios al onden público internacional". Traducción libre. CORTE DE APE1.ACIONES DE PARIS, Infracor Cofor v: Gugnam, 1985. En: Rev. Arb. No. 299.

Sobre esta decisión, ha comentado la doctrina: "la única relación entre el orlen publico internacional bajo el articulo $15025^{\circ}$ y ef onten piblico doméstico francés es meramente negativa: conto of orden priblico internacional esta en el corazin del orden piblico domestico, una regla qute no es ni siquiera un asunto de orden puiblico doméssico no pertria ser considerado como perteneciente al aricn publico internacional. En contraposicitin, se ha angumentade algunas veces que el onlen priblico al que se refiere el articulo $15025^{\circ}$ dehe ser interpretado como un 'verfadero orden priblico internacional', que puede definirse como orden priblico derivado de la comparacion de las exigencias fundamentales de los derechos nacionales y. particularmonte, del derecho internacional. EI concepto de 'verdadem onden público international' es perfectamente legitimo cuando se aplicu por los árbitros, quienes no pertenecen a ningin sistema legal particular... [Sin emburga] el orden piblico internacional al que se refiere el articulo 1502 5" puede ser sälo la comcepción francesa de orten priblico internacional o, en otras palabras, el conjauto de valores cana vialación no podria ser solerada por et ordenamiento juridico francés, inclusive en casos internacionales." Traducción libre. GAILLARD, Emmanucl y SAVAGE, John (Eds.). Fouchard Gaillard Goldman on Internotional Commencial Arbitration. Kluwer Law International, 1999, pp. 954-955. Nótese que se ha desarrollado una concepción nacional de orden público, mas flexible, destinada a ser aplicada en el contexto del arbitraje internacional, que funge como estóndar fundamental para determinar qué es y qué no es arbitrable, confundiendo de esta forma los límiles de uno y otro concepto. Asi, han stēalado las cor.

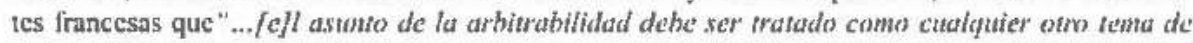
orten publico internacional: las curtes que revisen el laulo deben aplicar los conceptess de orden priblico internacional recanocidos en stus propio ordenaniento juridico, mientras que los arbitros deben deverminur por sí mismos las condiciones [que impone] el verdadero onlen público internacional". Traducción libre. GAILLARD, Emmanuel y SAVAGE, John (Eds.). Fouchard Gaillard Goldman on International Conmercial Arbitration. Kluwer Law International, 1999, p. 317. 
sujetos a un mecanismo privado de resolución de conflictos, sino que deben dejarse en manos del Estado. En este contexto, son numerosos los casos en los que se ha alegado la inarbitrabilidad de la materia objeto de la disputa, para objetar la jurisdicción del tribunal, buscar la anulación del laudo, o evitar su ejecución.

\subsection{Arbitraje de inversión}

En contraste con el arbitraje comercial internacional, el concepto de arbitrabilidad parece prima facie ajeno al arbitraje de inversión. Pues bien, el propósito de esta sección es precisamente identificar si es posible aplicar este concepto en el marco del arbitraje de inversión. Para tal fin, se hará especial énfasis en la noción de arbitrabilidad objetiva.

Como se dijo anteriormente, en el arbitraje comercial internacional la regla general es que las disputas son arbitrables. En consecuencia, la excepción es que ciertos tipos de disputas se reservan a las cortes nacionales.

En el arbitraje de inversión, la expresión 'arbitrabilidad ratione materiac' tendría una connotación restringida. En términos generales, la arbitrabilidad depende de la existencia de una inversión. Es decir, los únicos temas que serían susceptibles de resolución por parte de un tribunal arbitral serían los relacionados con una 'inversión', según la definición que de dicho vocablo provea el tratado respectivo. Sin embargo, este criterio (es decir, la definición de inversión en el tratado como limitante de la materia arbitrable) ha venido a ser complementado por dos estándares adicionales, que también podrían identificarse como criterios de arbitrabilidad de una disputa de inversión. En primer lugar, se identifica el desarrollo de una noción de inversión en la jurisprudencia arbitral y, en segundo lugar, se observa que los tratados incluyen -además de la definición de inversiónciertas condiciones para que la inversión sea susceptible de protección bajo el instrumento. Ambos criterios han venido restrin- 
giendo el ámbito de lo que, bajo las disposiciones de un tratado de inversión, sería arbitrable.

En efecto, además de la definición de inversión provista por el tratado, es importante considerar la controversia que ha surgido en relación con la definición de inversión en el contexto del CIADI y, en términos más generales, sobre la posible existencia de una definición inherente de inversión que actúe independiente del sistema procesal en el que se desarrolle el arbitraje. Aunque escapa al propósito del presente artículo discutir en detalle esta controversia, resulta suficiente señalar que la arbitrabilidad de una disputa de inversión podría depender del enfoque adoptado por el tribunal al respecto. ${ }^{11}$

Por otro lado, algunos tratados consagran definiciones amplias de inversión y no incluyen condiciones adicionales para su protección. Otros instrumentos contienen restricciones estrictas en relación con la inversión objeto de protección. Así, los Estados receptores pueden optar por limitar el tipo de inversión que desean proteger, incluyendo en los acuerdos ciertas condiciones, tales como la necesidad de aprobación de la inversión, la exigencia de que la inversión 'se haga de acuerdo con las leyes del Estado receptor' o la exclusión de actividades o sectores económicos del campo de aplicación del tratado y, de esta manera, del arbitraje de inversión.

Es en este contexto que se analizará la pregunta sobre la ilegalidad de la inversión como límite para la arbitrabilidad de las disputas de inversión. ${ }^{12}$ Recurrir a esta noción de arbitrabilidad podría ser útil para decidir si los alegatos acerca de la ilegalidad de la inversión se deben considerar como un asunto de jurisdicción o de mérito, teniendo en cuenta además el tipo y momento de presentación de tales alegatos.

11. Véase la sección 3.2.1.1 de este artículo.

12. Es importante anotar que la posibilidad de arbitrar una disputa de inversión está sujeta al cumplimiento de los demás requisitos exigidos por el tratado respectivo y, de ser el caso, por el Convenio sobre Arreglo de Diferencias a Inversiones entre Estados y Nacionales de otros Estados (en adelante, Convenio CIADI o el Convenio). 
Adicionalmente, el concepto de arbitrabilidad puede ser relevante no sólo para el tribunal arbitral en el sentido descrito anteriormente, sino también para quienes deciden los recursos de anulación o las solicitudes dirigidas al reconocimiento y ejecución de los laudos.

En este punto es fundamental considerar además la diferencia entre los laudos emitidos bajo el Convenio CIADI y aquellos que no cubre dicho instrumento. Los recursos contra los segundos, al igual que su ejecución, están sujetos al control de las cortes nacionales competentes y a la ley de la sede de arbitraje o del lugar de ejecución. En esta medida y teniendo en cuenta las disposiciones de la Convención de Nueva York y de la Ley Modelo CNUDMI, la inarbitrabilidad del asunto objeto de la disputa sería causal de anulación del laudo o de la denegación de su ejecución ${ }^{13}$. La manera como las cortes interpretarán estas causales permanece incógnita.

De otro lado, en relación con los laudos CIADI, $1+$ el Artículo 52 del Convenio establece las causales de anulación de un laudo, sin contemplar expresamente entre ellas que 'el asunto de la disputa no sea susceptible de solución por vía de arbitraje'. Sin embargo, pueden surgir cuestiones de arbitrabilidad en el proceso de anulación de un laudo CIADI, en el marco de las causales del artículo 52 (en particular, de la causal relativa al desbordamiento del tribunal en el ejercicio de sus atribuciones). ${ }^{15}$ De hecho, en los casos Patrick Mitchell c. la República Democrática de Congo (en adelante, Mitchell c. Congo) y Malaysian Historical Salvors SDN BHD and Malasin (en adelante, MHS c. Malasia), se

13. Véase, Convención de Nueva York, 1958, art, V.2.a: CNUDMI, Ley Modelo de Arbitraje Comercial Internacional, 1985, art. 36.1.b.i \& 34.2.b.i.

14. En este punto es preciso recordar que en 1978 el Conscjo Administrativo del CIADI cré el mecanismo complementario que permite realizar un arbitraje con el apoyo administrativo del ClADI y provee un reglamento de arbitraje propio, en aquellos casos que no se encuentran cobijados por el Convenio. Los laudos dictados bajo el mecanismo complementario no se encuentran exentos del escrutinio de las cortes nacionales. Véase, DOLZER, Rudolf y SCHREUER, Christoph, Principles of International Investment Law, Oxford, 2008, pp. 224-225. Para efectos de este articulo, la expresión 'laudo CIADI' se utilizará para hacer referencia a las providencias arbitrales amparadas por el Convenio CIADI.

15. Convenio CLADI, articula 52(1)(b). 
planteó la pregunta sobre el exceso en el ejercicio de las atribuciones del tribunal en razón de la materia arbitrable; particularmente, se discutió en ese contexto la existencia de una definición de inversión más allá de la literalidad de los tratados. ${ }^{16} \mathrm{Al}$ final del día, la cuestión en dichos casos residía en si la disputa era arbitrable desde el punto de vista de la materia objeto de controversia, es decir, si la disputa concernía a un asunto de inversión.

Finalmente, en la medida en que la ejecución de los laudos CIADI debe darse de manera automática por las cortes nacionales en virtud del artículo 54 del Convenio y, por lo tanto, no está sujeta a las disposiciones de la Convención de Nueva York, la pregunta sobre la incidencia de la noción de arbitrabilidad no parece prima facic relevante en relación con estas providencias.

\section{Arbitrabilidad e Ilegalidad}

\subsection{Arbitraje comercial internacional}

En el arbitraje comercial internacional la resolución de los asuntos de corrupción, soborno y otros actos ilegales por medio del arbitraje, que originalmente sufrió fuertes restricciones, ha sido objeto de una evolución que ha llevado a considerar tales materias como arbitrables hoy en día. ${ }^{17} \mathrm{La}$ renuencia a arbitrar disputas relacionadas con temas de corrupción se encuentra en laudos arbitrales tempranos, tales como la decisión proferida en 1963 por Gunnar Lagergren como árbitro único en un caso CCI. ${ }^{18}$ El árbitro Lagergren tuvo que pronunciarse sobre el enfoque que

16. Para los detalles de la discusión sobre estos casos, véase la nota de pie de página No. 41.

17. Por ejemplo, haciendo referencia al derecho suizo, se ha concluido que "[a] pesar de los requisitos del orten puiblico suizo sohre este asunto, parece que les tribunales arbitrales generalmente admiten actualmente la arbitrabilidad de disputas que envuehen alegaciones de corrupción... ". Traducción libre. GAILLARD, Emmanuel y SAVAGE, John (Eds.). Fouchard Gaillard Goldman on International Commercial Arhitration. Kluwer Law International, 1999, p. 355.

18. Caso CCI No. 1110, Laudo, 1963, cn 10 Arb. Int? 282, 1994. 
debía adoptarse frente a la resolución de una disputa en la cual se habían elevado alegaciones serias de soborno.

En este caso, las partes celebraron un contrato mediante el cual la demandada, una empresa británica, se obligaba a pagarle a la demandante, un ingeniero y empresario argentino, un porcentaje del precio de los contratos de suministro de equipos eléctricos que se llegaren a firmar entre la demandada y las autoridades argentinas. Luego de que el primero de tales contratos fuese asignado a la demandada, ésta se rehusó a pagar la comisión acordada con la demandante, quien decidió dar inicio al arbitraje. En su defensa, la demandada alegó que los servicios solicitados a la demandante consistían en ejercer su influencia en las decisiones de los oficiales del gobierno argentino con el fin de que le fueran asignados los contratos. A pesar de que ambas partes estaban de acuerdo en cuanto a que el árbitro único tenía competencia para oír su caso, éste decidió que no tenía jurisdicción al considerar que la disputa se refería a una grave violación de las buenas costumbres y el orden público internacional que no podía ser decidida por un tribunal arbitral. Al respecto, el árbitro sostuvo que "las partes que se involucran en una empresa de este tipo se deben dar cuenta que han perdido todo derecho a solicitar ayuda al sistema de justicia (cortes nacionales o tribunales arbitrales) para resolver sus disputas." ${ }^{19}$ En su momento, la interpretación que se le dio a esta decisión consistió en que las disputas que involucraran temas de corrupción e ilegalidad no eran susceptibles de ser resueltas mediante arbitraje.

Sin embargo, la jurisprudencia arbitral ha evolucionado desde el precitado fallo y, en la actualidad, es cada vez más frecuente que los tribunales no se declaren faltos de jurisdicción por tal motivo y decidan sobre disputas comerciales que involucren asuntos de ilegalidad o corrupción. Más aún, la opinión general es que una prohibición de arbitrar controversias que tengan un matiz de ilegalidad sería incompatible con la Convención de Nueva York.20

19. Traducción libre. Caso CCI No. 1110, Laudo, 1994,10 Arb. Int'1 282 (1994). 
Esta tendencia se sustenta además en la doctrina de separabilidad de la cláusula arbitral o compromisoria. ${ }^{21}$ De esta forma, aún cuando el contrato contentivo del pacto arbitral estuviere afectado de alguna forma por cuestiones de ilegalidad, o hubiere sido obtenido mediante fraude o corrupción, la cláusula arbitral no se vería afectada por tal circunstancia, en tanto que se la considera independiente.22 El efecto práctico de este enfoque es que el tribunal mantiene su jurisdicción para decidir sobre los alegatos que se relacionen con la ilegalidad del contrato subya-

20. BORN, Gary. International Commercial Arbitration. Wolters Kluwer, 2009. pp. 788, 804 \& 838.

21. Es preciso anotar que el articulo utiliza el término 'separabilidad' y no 'autonomia' en aras de la precisión, en consideración a que "Fe]l principio fundamental que rige a los pacles arbitrales internaciomales es el de su autonomia. Sin embargo, debe enfatizarse desde el camienzo que el teirmino tiene un doble sentido. Algunas veces se utiliza en su significado tradicional, que es el que se reficre a la autonomia o separabilidad del pacto arbitral del contrato principal con el gue se relaciona. A veces. sin embargo, las cortes, especialmente en Francia, se refieren a la autonomia del pacto arbitral de 'todos los derechos nacionales', que es un concepto completamente diferente... ". Traducción libre. GAILLARD, Emmanuel y SAVAGE, John (Eds.). Fotichand Gaillart Goldman on International Commercial drbitration. Kluwer Law International, 1999, §388. La doctrina de separabilidad del acuerdo arbitral corresponde al primero de los conceptos señalados arriba, y consiste en que "...IJ a cläusula compromisoria es autinoma y juridicamente independiente del contrato principal que la conticne". Traducción libre, Caso CCI No. 8938, Laudo final. En: XXIVa Y.B. Comm. Arb. 174, 176, 1999.

22. El principio de scparabilidad del pacto arbitral no es una novedad. Ya en 1918 afirmaba una corte alemana que "...la clatusula arbitral puede tener una existencia independiente, de tal manera que dehe aplicar también a decisiones respecto de la valide del contrato principal...". Traducción libre. OBERLANDESGERICHT MARIENWERDER, Sentencia, 12 de diciembre de 1918, En: Leipziger Zeitschrif für Deutsches Recht 501. Más explicitamente, la Corte de Casación francesa afirmaba cn 1963 que "... [c]n temas de arbitraje internacional, el pacto arbitral, concluido separadamente o inchido en el acto juridico con el que se relaciona, siempre tiene, salvo en circunstancias excepcionales, una completa autonomia juridica, que exchove que pueda ser afectado por la eventual invalidez de tal acto...". Traducción libre. COUR DE CASSATION, Ets Raymond Gossel c. Carapelli, 1963. Asimismo, en 1967, la Corte Suprema de Justicia de los Estados Unidos decin que "...salvo donde las partes pretenden lo contrario... les pactos arbitrales son 'scparables' de les contratos a los que estain incorporados... ". U.S. SUPREME COURT OF JUSTICE, Prima Paint Corp. v. Flood \& Conklin Mffg Co.. 388. U.S. 395, 1967. De manera similar, cl Tribunal Federal Suizo ha establecido que "...el pacto arbitral no puede ser atacado poryue el contrato principal no es válido... En consectencia, el derecho suizo reconoce el principio de autonomia del pacto arbitral, un principio adoptado en la jurisprudencia por cuatro décadas... y utiversalmente aceptado en Europa Occidental y. en los Estados Unidos, hajo les conceptos de 'severubility'o separability'...". Traducción libre. TRIBUNAL FEDERAL SUIZO, National Power Corp. c. Westinghouse, 1993. Asimismo, en Bremer Vulkan, la Cámara de los Lores británica aseveró: "... [e]l pacto arbitral constituye un contrato autocontenido colateral o complementario del [contrato subyacenic]...". HOUSE OF LORDS, Bremer Vulkan Schifbau und Maschinenfabrik c. South India Shipping Corp. Lid., 1981. En: A.C. 909, 980. La Corte de Apelaciones de Inglaterra ha sostenido la misma posición; en efecto, en 1992, dicha corporación afirmaba: “.... [u]n reconocimiento pleno del principio de separabilidad ticnde a facilitar el comercio internacional...". ENGLISH COURT OF APPEAL, Harhour Assurance Co. c. Kansa General International Insarance Co. En: 3 Alt E.R. 897, 1992. Basten estos cjemplos para mostrar que el principio ha tenido una indiscutible acogida en la jurisprudencia. 
cente y que hacen parte de la discusión de fondo del caso. ${ }^{23}$ Cabe anotar que las cortes nacionales conservan el control sobre los asuntos relacionados con alegatos de ilegalidad en la etapa de anulación y ejecución del laudo, debido a que están facultadas para determinar si los contratos o transacciones afectados por la ilegalidad, son contrarios al orden público. ${ }^{24}$

Finalmente, resulta relevante considerar la pregunta sobre las facultades del tribunal arbitral para abordar los temas de ilegalidad cuando éstos, aunque no han sido planteados por las partes, se hacen patentes en el curso del proceso. Algunos argumentan que un tribunal arbitral tiene el deber y la responsabilidad de exponer y resolver dichos temas de acuerdo con la ley aplicable sua sponte; otros sostienen que, al iniciar su propia investigación sobre asuntos que no han sido expuestos por las partes, el tribunal arbitral corre el riesgo de exceder los límites de su jurisdicción. ${ }^{25}$ Además, el tribunal debe enfrentar otras

23. Algunos autores señalan que la cuestión de arbitrabilidad no afecta la validez del pacto arbitral y que. por lo tanto, no genera efecto alguno sobre la jurisdicción del tribunal; màs bien, influye sobre la cjecutabilidad de las pretensiones. Véase, YOUSEFF, Karim, "Part I. Fundamental Observations and Applicable Law Chapter 3 - The Death of Inarbitrability", en: MISTELIS, Laukas A y BREKOU. LAKIS. Stavros L. (Eds), Arbitrability: Imternational and Comparative Perspectives, Kluwer Law International, 2009, pp. 1-18, pár. 3-23.

24. Véase Soc. European Gas Turbines S.A. c. Soc. Nestman internacional Lfd, donde la Corte de Appelaciones de Paris anulo un laudo arbitral considerando que su cjecución constituiria una violación del orden pủblico internacional. Durante el arbitraje, Westman reportó de manera fraudulenta los gastos que alegó como prucbas del cumplimiento de sus obligaciones contractuales con EGT. Este último alegó que cjecutar un laudo arbitral basado parcialmente en un reporte de gastos fraudulento seria semcjante a validar la comisión de un fraude. La Corte de Apclaciones de Paris acogió los argumentos de EGT y anuló las secciones del laudo que se encontraban afectadas por el fraude de Westman, de conformidad con el principio legal de fraus ommia corrumpit. Véase: CORTE DE APELACIONES DE PARIS, Soc. European Gas Turbines S.A. c. Soc. Nestman inkernacional Lul. En: Revuc, Vol. 83. 1994.

Adicionalmente, EGT buscó la anulaciön del fallo alegando que cl objeto real de! contrato cra ilicito al comprender el tráfico de influencias. La Corte de Apelaciones desechó esta demanda, estimando que no habis prucba suficiente de que el contrato hubiera sido obtenido de mancra ilicita. CORTE DE APELACIONES DE PARIS, Soc. European Gas Turbines S.A. c. Soc. Nestman internacional Lud. En: Yearbook Commercial Arbitration, Vol. XX, Kluwer Law Intemational, 1995, pp. 198-207.

25. En ese sentido, RICHARD KREINDLER ha afirmado: "- [e]stú el árbitro atrapado entre la espa. da y la pared al iniciar su propia verificacion de la ilegalidad sospechada, a pesar de que las partes no han alegado la ilegalidad? El no inmiscuirse en tal investigaciön por su cuenta puede hacer que el árbitro pase a ser "cómplice" en un contrato contrario a la moralidad puiblica, o que proficra un laudo que viole el orden público. Iniciar su poppia investigación, por otro lado, y en particular for. mular sus propias conciusiones acerca de dicha ilegalidad en su latudo, puede constituir una incursión no permisible en una disputa "no contemplada o no includida dentro de los términos de la demanda arbitral, o contentisa de decisiones sobre asmutos mais alla del ambito de la demanda arbitral ... ". 
dificultades relacionadas con la recolección de la evidencia que pruebe la ilegalidad, la definición de los estándares de valoración de dicha prueba y, finalmente, la consecuencia jurídica de la ilegalidad, en caso de que ésta sea acreditada en el proceso. ${ }^{26}$

\subsection{Arbitraje de inversión}

En general, los asuntos relacionados con ilegalidad y corrupción surgen en el arbitraje de inversión de forma diferente. El perfeccionamiento del consentimiento en esta clase de arbitraje es una transacción no simultánea, que supone manifestaciones independientes de consentimiento por parte del Estado demandado y del inversionista demandante. No existe una cláusula arbitral en el sentido clásico del término. Por lo tanto, el principio de separabilidad no sería aplicable y el tema de arbitrabilidad se debe plantear de forma diferente.

Algunos autores han argumentado que, de la misma forma en que la cláusula arbitral se puede separar del contrato en un arbitraje comercial de manera tal que no se verá afectada por la suerte de éste, el tratado constituye la base independiente de consentimiento para someter una disputa de inversión a arbitraje, diferente del contrato a través del cual se canalizó la inversión. Así, las cuestiones de ilegalidad y corrupción que afecten a este último, no tendrían impacto alguno sobre el instrumento internacional. En ese sentido, se ha observado que:

"La misma conclusión debería alcanzarse en relación con arbitrajes basados en tratados. El caso sería aquel en el que el contrato de inversión que dé lugar a un arbitraje bajo un TBI o CIADI, haya sido obtenido mediante la corrupción del

Traducción libre. KREINDLER, RICHARD. Aspects of llegaling in the Formution and Performance of Contracts. En: VAN DEN BERG, Albert Jan (Ed.), International Commercial Arbitration: Importun Contemporary Questions, Kluwer Law Interational, 2003, pp. 236-237.

26. Cabe anotar que esta preocupación no es exclusiva del arbitraje comercial haciéndose extensiva al arbitraje de inversión, cuyos matices públicos caracteristicos suponen la necesidad de tomar en cuenta consideraciones adicionales. 
representante del Estado o de una entidad pública. En tales casos, la corrupción alegada no puede afectar la validez del tratado en el que se funda el consentimiento para arbitrar, y la consecuencia será nuevamente la inadmisibilidad de las pretensiones del inversionista." 27

Este enfoque parece haber sido el adoptado por el tribunal en Plama c. Bulgaria, en su decisión sobre jurisdicción, donde afirmó:

"En cualquier caso, el Tribunal señala que los cargos de falsedad [misrepresentation] no están dirigidos específicamente contra el pacto arbitral de las partes, contenido en el articulo 26 del ECT. La falsedad alegada se refiere a la transacción relativa a la venta de las acciones de Nova Plama por $E E H$ a PCL, y a la aprobación de ésta dada por Bulgaria en el Acuerdo de Privatización, entre otros. No es en estos documentos donde el pacto arbitral aparece. El acuerdo de Bulgaria para arbitrar se encuentra en el ECT, un tratado multilateral, un documento completamente separado. El demandado no ha alegado que la aparente falsedad del demandante generó la nulidad del ECT o su consentimiento para arbitrar, contenido en el ECT. Así, las disposiciones del ECT, incluyendo el artículo 26, no sólo son autónomas y separables de la Parte III de ese tratado, sino que son independientes de la totalidad de la transacción relativa a Nova Plama; de ahí que, aún si el acuerdo de las partes acerca de la compra de Nova Plama es aparentemente inválido a causa de la falsedad del demandante, el pacto arbitral continúa siendo efectivo." 28

Sin embargo, este enfoque no refleja la realidad del consentimiento necesario para dar lugar a un arbitraje de inversión, ni determina cómo la ilegalidad puede afectar la arbitrabilidad de

27. Traducción libre. MOURRE, Alexis, "Part II. Substantive Rules on Arbitrability. Chapter II Arbitration and Criminal Law: Jurisdiction, Arbitrability and Duties of the Arbitral Tribunal", en in MISTELIS, Loukas A. y BREKOULAKIS, Stavros L. (Eds), Arbitrabilin: International and Comparative Perspectives, Kluwer Law International, 2009, p. 213, pir. 11-13.

28. Traducción libsc. Plama Consortium Limited c. Bulguria, Caso CIADI No. ARB/03/24, Decisión de Jurisdicción, 8 de febrero de 2005, pár. 130. 
ciertos asuntos, generando una restricción a la jurisdicción del tribunal arbitral ratione materine. El tratado no es un acuerdo para arbitrar que pueda separarse de la transacción realizada por las partes en el arbitraje: las partes del tratado son diferentes de aquellas que suscriben el contrato. La pregunta no se relaciona entonces con la validez del pacto arbitral, sino con el alcance del consentimiento otorgado por el Estado y los límites de la noción de inversión.

Aunque la pregunta sobre la existencia de una inversión afectada por cuestiones de falsedad y fraude fue formulada por el estado demandado en el caso Plama c. Bulgaria, ${ }^{29}$ debido al momento en que se presentó tal pretensión, el tribunal decidió tratar los alegatos sobre la supuesta falsedad en las declaraciones hechas por el inversionista al Estado receptor, durante la etapa de mérito. En consecuencia, los árbitros afirmaron que tenían jurisdicción en los términos anteriormente citados..$^{30} \mathrm{El}$ tribunal encontró posteriormente que los alegatos sobre la falsedad y el fraude eran de recibo y, por consiguiente, la inversión no se encontraba protegida por el tratado, por contrariar no sólo legislación interna de Bulgaria sino -especialmente- algunos principios del derecho internacional, tales como la buena fe, los principios nemo auditor propriam turpitudinem allegans y ex turpi causa así como la noción de orden público internacional.

Es importante anotar que en este caso el tratado relevante, la Carta de la Energía, no disponía expresamente que la inversión debiera cumplir con la legislación del Estado receptor para ser considerada como tal. Esto puede explicar la dificultad con que

29. En el caso, "cl demandado afirmaba, en la audiencia de septiembre, que no habia una 'inversiỏn' bajo el articulo I(6) ECT, porque el demandante habia incurrido materialmente en falsedad [misrepresentation], o se habia abstenido dolosamente de dar a conocer la verdadera propiedad del demandante a las autoridades búlgaras, en violación de la ley bủlgara. En consecuencia, cl consentimiento de la Agencia de Privatización de Bulgaria para la compera de las acciones de Nova Plama por el demandante, era nulo ante cl derecho búlgaro; de ahí que el demandante nunca hubicra hecho una inversión válida". Plama Consortium Limited c. Bulgaria, Caso CIADI No. ARB/03/24, Decisión de Jurisdicción, 8 de febrero de 2005, par. 126.

30. De hecho, no fue sino hasta la audiencia sobre jurisdicción que Bulgaria elevó su pretensión sobre falsedad [misrepresentation], cuando la evidencia presentada al tribunal incluia elementos suficientes para hacer tal afirmación. 
se encontró el tribunal para decidir sobre la pretensión de Bulgaria en la etapa de jurisdicción, entrándola a considerar como una cuestión de arbitrabilidad, esto es, de la materia que puede ser objeto de arbitraje por encontrarse dentro del ámbito de la definición de inversión.

La posibilidad de que los argumentos sobre ilegalidad de la inversión puedan afectar la jurisdicción de un tribunal arbitral dependerá también de la parte que presente el alegato: el inversionista planteará generalmente el asunto como una violación a la obligación de protección del Estado bajo el tratado; por su parte, el Estado la elevará como una objeción a la jurisdicción del tribunal y a las pretensiones del inversionista demandante.

Si el inversionista da inicio al proceso arbitral alegando la violación de las obligaciones del tratado de inversión argumentando que el Estado demandado incurrió en actos ilegales -como fraude o corrupción-en relación con la inversión, no habrá duda alguna acerca de la jurisdicción del tribunal, a menos que el Estado plantee una objeción relacionada con la 'arbitrabilidad', arguyendo que la disputa no es arbitrable por no existir una inversión o, habiéndola, porque ésta no cumple con las condiciones adicionales establecidas en el tratado de inversión por adolecer de una ilegalidad.

En realidad, la naturaleza flexible de las protecciones otorgadas por los tratados de inversión ha permitido a los inversionistas presentar reclamos bajo estándares diferentes por violaciones del tratado. Hasta ahora ningún tribunal ha proferido un fallo de fondo sobre dichos reclamos, ya sea porque no se ha encontrado evidencia suficiente que sustente dichas demandas ${ }^{31}$

31. Véase por cjemplo el caso Bayindir c: Turquia en el que el tribunal, después de revisar numerosos documentos que aparentemente demostraban la intención de favorecer a los contratantes locales, encontró que "...en cl expediente no hay fiundamemo para cl alegato de corrapción [prescntado por] Bayindir en el proceso de licifacion...". Traducción libre. Bayindir Insaat Turizm Ticaret Ve Sanayi A.S. c. Pakistan, Caso ClADI No. ARB/03/29, Laudo, 27 de agosto de 2009, pár. 300.

En el caso de Afethanex v: USA, el inversionista alego que el principal productor estadounidense de alcohol, Archer-Daniels-Midland (ADM), influenció ilicitamente al Estado de California en la decisión de prohibir el uso de MTBE - un aditivo para la gasolina- en detrimento de Methanex. En par- 


\section{o porque los demandantes de algún modo han desistido de sus pretensiones. ${ }^{32}$}

Sin embargo, los tribunales han indicado que, de ser comprobada, la corrupción constituiria una violación de las protecciones otorgadas por el tratado y del derecho internacional público en general. ${ }^{33}$ Los tribunales también han destacado la importancia que pueden tener este tipo de alegatos en la evaluación general del caso y han abordado el tema de las atribuciones

ticular, se afirmó que el gobemador Gray Davis recibio dinero de ADM para su campaña y se reunió en secreto con cjecutivos de dicha compañia. El Tribunal encontró que "...(i) el gobernador de California, seviour Gray Dasis... profirió la Onden Ejecunira D.4.99 sin intenciou alguna de perjudicar el metunol o a Methanex, y sin ninguna intenciön de favorecer el etanol o a ADM, contrario a los alegatos de Methanex, y (ii) no hav evidencia creible de que el señor Davies, como gobernador de California, o California, pretendieran fanorecer posteriormente la industria de ctanol to industrias particulares del sector, incluyendo a ADM) o causar daño a los productores extranjerns de metanol (incluyendo a Methanex). contrario a los alcgatos de Mcthanex...". Traducción libre. Methanex Corporation c. United States of America, Laudo final de jurisdicción y fondo CNUDMI (NAFTA), 3 de agosto de 2005, Parte III, Cap. B, pár. 60.

32. Por ejemplo, en F-W Oil Interest (FIVO) c. Trinidad \& Tabago (T\&T), el tribunal no entró a examinar el fondo de los alegatos de corrupción contra el demandante, afirmando que: "...lo que cn la soli. citud de arbitrajc parccia ser un caso sobre an incumplimicnto contractual se transformo, con la presentacion del Memorial, en un caso que gira en torno a serios alegatos de corripción contra altos funcionarios del Estado demandado... Afortumadamente no hay necesidal de recortar aqui el fondo de ninguno de estos alegatos, en vista de la manera como el caso finalmente se desarmillo. El tribunal está obligado simplemente a indicar cómo una parte sustancial del caso, tal como fié alegado. asi como de la evidencia que le fite prescntata, giraban en torno de estos alcgatos antes de que fueran, en efecto, ahandonados por el demandante y no persistidos por el demandado... una vez que las partes ahandonaron dichos alcgatos, dejo de haber cualquicr razin para que ef tribunal se promu!ciara sobre ellos, y existian todas las razones para no hacerlo... no es parte de la finción de un tributal como éstc, hacer juicios morales sobre el comportamiento de una " otra parte, o inclusive amhas partes, sino simplemente decidir sobre la validez de las pretensiones elevadas, y sobre sus consecucncias juridicas. No debemos, sin embargo, dejar el astunto simplemente ahi, sin dejar claro yuc este tribunal (como, asumimos, cualquier tribunal ClADl), debe tomar la más seria consideracioin de los alegatos de cornupción -si son soportados por evidencia adecuada. Esto no ocurne simplemente por los afectos potenciales de tales alegatos sobre las personas involucradas, sino también per el nefasto y pernicioso efecto que la corrupcioin ha demostrado tener sobre el desarrollo económico (notablemente en paises en vias de desarrollo), y al desarrollo econimico es finalmente el propésito para cuy a consecución fueron creados los tratados bilaterales de inversión y el Banco Mundial mismo. Se sigue que, si se han hecho alcgatos ale corrupción, y se ha probado que están debidamente fundamentados, tendrian que tener el más sustancial efecto sobre la visión del caso adoptada por el tribunal...". Traducción libre. F-II Oil Interest Inc. c. Repuiblica de Trinidad y Tohago, Caso CIADI No. ARB/0I/14, Laudo, 3 de marzo de 2006, pár. 210-212.

33. Aunque el tribunal encontró que ta falta de evidencia clara y convincente le impedia abordar los méritos de la demanda presentada por EDF, los árbitros establecieron que "....una solicitud de soborno por parte de una agencia estatal es una violacioin de la obligación de trato justo y equitativo, debida al demandante bajo el TBI, asi como una infracciiin al orden püblico internacional" y que "ejercer la discrecioin de un Estado sobre la basc de la corrupcion es un [...] incumplimiento esencial de la transparcncia y las expectativas legitimas... ". Troducción libre. EDF (Services) Limited c. Rumania, Caso CIADI No. ARB/05/13, Laudo, 8 de octubre de 2009, pár. 221. 
de los árbitros -en especial de los comités de anulación ad hoc ${ }^{3+}-$ para decidir sobre los alegatos de corrupción que el demandante no haya expuesto ante el tribunal original.

Es preciso anotar que, en general, los tribunales no se han abstenido de considerar estos temas en razón de la naturaleza de la ilegalidad de los reclamos, ni se han declarado faltos de jurisdicción para decidir sobre los mismos.

Así las cosas, para que los alegatos de ilegalidad, fraude y corrupción afecten la jurisdicción del tribunal, éstos deberán ser presentados por el Estado demandado como defensa durante la etapa jurisdiccional. Para ello, será necesario vincularlos con la definición de inversión y el cumplimiento de las condiciones adicionales relativas a la inversión contenidas en el tratado. Es esta defensa la que puede ser planteada en términos de arbitrabilidad en el contexto del arbitraje de inversión.

\subsubsection{Las defensas presentadas por el Estado para objetar la jurisdicción del tribunal arbitral relacionadas con la ilegalidad de la inversión}

La definición de inversión ha sido utilizada frecuentemente por los Estados para controvertir la jurisdicción de los tribunales arbitrales, particularmente a partir de alegatos de ilegalidad, fraude y corrupción. ${ }^{35}$ De conformidad con la noción de arbitrabilidad ratione materine que acoge el presente artículo, estas cuestiones actuarían entonces como restricciones a la posibilidad de que ciertas disputas sean resueltas mediante arbitraje, limitando en consecuencia la jurisdicción del tribunal.

34. En el caso RSM c. Granada, la manera en que el demandante presentó su caso y, posteriormente, su solicitud de anulación ante el Comité $A d H o c$, impidió al tribunal inicial pronunciarse sobre los alegatos de corrupeión y dio lugar a planteamientos interesantes acerca de los poderes de los comités de anulación para decidir sobre temas de hecho y derecho no sometidos al tribunal original. RSM Production Corporation c. Granada, Caso CIADI No, ARB/05/14. Decisión sobre la solicitud de RSM de un fallo preliminar, 29 de octubre de 2009.

35. Es preciso anotar que el análisis se enfoca en los tratados de inversión y no entra a discutir las definiciones provistas por las leyes macionales de inversiön. 
Así, como se anunció anteriormente, la arbitrabilidad de una disputa en el marco del sistema de protección internacional de inversiones depende básicamente de dos elementos, a saber: (i) la definición de inversión provista por el tratado y, de ser el caso, los criterios jurisprudenciales que delimitan el alcance del concepto; y (ii) los parámetros o condiciones adicionales que establezcan los tratados de inversión, leyes o contratos relevantes.

\subsubsection{LA DEFINICIÓN DE INVERSIÓN EN LOS TRATADOS Y LOS CRITERIOS IURISPRUDENCIALES}

\section{Los tratados de inversión}

No existe una tendencia unívoca en los tratados de inversión respecto de la definición de 'inversión'. De hecho, algunos contienen una definición restrictiva del término, mientras que otros proveen una descripción más amplia. La primera tendencia se manifiesta especialmente en los tratados de inversión firmados antes de la década de 1990, que tendían a definir la noción de inversión vinculando el concepto a la noción de capital o al establecimiento de una empresa local..$^{36}$ Los tratados de inversión más recientes, incluyendo a aquellos basados en el modelo de la Organización para la Cooperación y el Desarrollo Económico (OCDE) y los modelos estadounidenses, han adoptado una definición amplia de 'inversión', perspectiva que puede manifestarse de al menos tres maneras diferentes.

Primero, una definición general, como sería el caso del TBI celebrado entre Ecuador y el Reino Unido, que define inversión como 'cualquier clase de activo' y provee una lista de ejemplos no taxativos de lo que podría constituir una inversión. ${ }^{37}$

36. RUBINS, Noah. The Notion of 'Investment' in Internacional Investment Arbitration, en: HORN, Norbert y KRÖLL, Stephan, Arbitrating Foreign Investment Disputes, 2004, p. 291.

37. Acuerdo entre el Gobiemo del Reino Unido de Gran Bretaña e Irlanda del Norte y el Gobicmo del Ecuador para la promoción y protección de las inversiones, $10 \mathrm{de} \mathrm{mayo} \mathrm{de} \mathrm{1994.} \mathrm{Otro} \mathrm{ejemplo} \mathrm{es} \mathrm{el}$ 
Segundo, una lista taxativa de actividades económicas que podrían ser consideradas como inversiones. Ejemplos de este enfoque son el tratado de inversión Canadá-Chile y el Tratado de Libre Comercio de América del Norte (TLCAN), que además contiene un listado de actividades que no se consideran inversiones. ${ }^{38}$

Tercero, a través de una definición amplia de carácter general, combinada con una lista ilustrativa de actividades que pueden constituir una inversión; esta posibilidad fue seguida en tratados tales como el tratado de libre comercio entre Estados Unidos y Singapur. ${ }^{39}$

\section{Criterios jurisprudenciales}

Como resultado de la ausencia de definición de inversión en el Convenio CIADI, parte de la doctrina y de la jurisprudencia han considerado que dicho vocablo, en el contexto del sistema CIADI, designa aquellas actividades que cumplen una serie de condiciones, que a su vez fueron enunciadas en el laudo del caso Salini c. Marruecos (que suelen conocerse como el 'Test Salini'), a saber: (i) una contribución en dinero $u$ otros activos susceptibles de valoración económica; (ii) cierta duración; (iii) un elemento de riesgo, y (iv) una contribución al desarrollo del Estado receptor de la inversión. ${ }^{40}$

La pregunta sobre si estas condiciones son necesarias o contingentes para efectos de determinar la existencia de una inversión ha sido materia de discusión en varias decisiones de anulación. ${ }^{41}$ Por otra parte, estas condiciones fueron posteriormente

tratado de protección de inversiones de la Asociación de Naciones del Este de Asia (ASEAN, por sus siglas en inglés).

38. Tratado de libre comercio entre Chile-Canada, 6 de febrero de 1997, articulo. G-40; TCLAN, artículo 1139.

39. Tratudo de libre comercio entre Estados Unidos y Singapur ('USSFTA' por sus siglas en inglés), $6 \mathrm{de}$ mayo de 2003, articulo 15.1 (13).

40. Salini Costruttori SpA \& Anor c. Kingdom of Alorocco, Caso CIADI No ARB/00/4, Laudo de Jurisdicción, 23 de julio de 2001, pár. 52. 


\section{analizadas y modificadas por el tribunal del caso Phoenix c. República Checa, que consideró que ciertos principios generales}

41. Los casos Afichell c. Congo y MHS c. Afalasia, resultan ilustrativos. Asi, en el procedimicnto de anulación del caso Mfitchell c. Congo, el Comité al hoc decidió anular el laudo arbitral proferido el 4 de abril de 2004, "...por el manifiesto exceso de pexdery la ausencia de motivacion ... en la decisiön del Tribunal Arbitral de accptar su jurisdicción sobre la base de la existencia de una inversioin, seguin la noción fale inversion] de la Convención de Ilashington: tal anulacions aplica al lando en su conjunto, en virtud del articulo 52(3) de la Convencion". Traducción libre. Patrick Afitchell c. la Repuiblica Democratica de Congo, Caso CIADI No. ARB/99/7, Decisión de Anulación del Laudo, 1 de noviembre 2006, pár. 67. En cste caso, la Demandada alegó que: (i) la actividad adelaniada por Mitchell \& Associater no constituia una inversión dado que, por su naturaleza, no contribuia al desarrollo económico y social del Estado receptor; (ii) la asesoria legal prestada por Mitchell \& Associates no constituia una actividad comercial bajo los términos del tratado de inversión; (iii) la noción de senvicio utilizada por el tratado debia entenderse como una actividad comercial o económica relacionada con inversiones, lo que excluiria la consideración de la consultoria juridica como servicio; y (iv) la actividad en cuestión no cumplia con los requisitos objetivos de una inversión, en tanto que no era una operación a largo plazo, no sc habia matcrializado por medio de una contribución significativa de recursos y no ienia una relevancia suficiente para la economia del pais, que permiticra distinguirla de una transacción comercial ordinaria Patrick Mitchell c. la República Democrática de Congo, Caso CIADI No. ARB/99/7, Decisión de Anulación del Laudo, I de noviembre 2006, pár. 23.

El Comité Ad Hoc afirmó que "es necesario verificur la conformidad del conccpto de in ersién esfablecido en el acuerdo de las purtes o en al TBI, con el concepto de inversion en la Contención de Washington... ese concepto de inversion dehe prevalecer solve cualquier otra 'definiciön 'de inversiön en el acuerdo de las partes o en el TBI. ya que es obvio que los especiales y privilegiados arruglos establecidas por la Convenciön de Washington sỏlo pucte aplicarse al tipo de inversioin que previermu los Estados contratantes...". Traducción libre. Patrick Mitchell c. la Repuiblica Democrática de Congo, Caso CIADI No. ARB/99/7, Decisión de Anulación del Laudo, 1 de noviembre 2006, pár. 25. Hecha csta afirmación, el Comité al hoc consideró la existencia de una definición de inversión en el contexto CIADl, cuyos elementos constitutivos conforman un presupuesto neccsario para la configuración de una inversión susecptible de dar lugar a un arbitraje bajo el tratado. Los elementos en cuestión fucron: (i) cl compromiso del inversionista (financicro a a través de trabajo); (ii) la duración del proyecto; (iii) el riesgo cconómico relacionado con el proyecto (la falta de certeza sobre su éxito); y (iv) la contribución al desarrollo económico del Estado receptor. El Comité ad hoc se enfocó en el último elemento, calificándolo como esencial. Véase: Patrick Mitchell c. la Reptiblica Demescrútica de Congo, Decisión de Anulación del Laudo, Caso CIADI No. ARB/99/7, I de noviembre 2006, pár 27. Nótese que en este caso se cstablece la prevalencia de una definición de 'inversión' propia de la Convención de Washington, prevalente sobre la que establecia un tratado de inversión en particular. En contraste, en el caso MHS c. Malasia el Comití ad hoe encontró que, al declinar su jurisdicción, el Árbitro Único no habia justificado sufieientemente si el contrato de rescate marino concluido entre el Gobiemo de Malasia y Malaysian Historical Salvers cra una inversión. En ese sentido, afimmó: "...por los términos del dcuerdo y por sus fincs, el Contrato es ima inversión. El Arbitro Único no llegi a otra conchusion respecto del Acuenlo. Mais bien, eligio examinar, virfualmente de mameru exclusiva, el asumto de si habia ma imersión bajo el articulo 25 del Comenio CIADI. Encontrando que no la habia, decidió que es innecesario discutir si el Contrato es una 'inversión' hajo el TBI: Sin embargo, el Árbitro Único observó que 'anmegte el contrato proveia cierto beneficio a Afalasia'. no habia 'una contrihución suficiente al desarvollo conimico de Malasia para calificar como una 'inversion 'para efectos del articulo 25(I) o cl articuio I(a) del TBI: El (Arbitro Únicol presentó un extenso análisis en soporte de su conclusión respectu del Convenio ClADI, pero ninguno respecto de su conclusion acerca del TBI. El Comite no ha podido ver que findamtento pudo haher presentado el dirbitm Único para sostener la conclusiòn de que el Contrato y,su implementación no constituycen una inversión, se'guin la nociein prevista por dicho dcuento. Por cl contrario... es clam que el contrato y su ejecución por Sahor constituycn una inversion, seguin se define dicho vocahlo en el denerio". Traducción libre. Malaysian Historical Salvars SDN BHD c. At, Caso CIADI No. ARB/05/10, Decisión sobre Solicitud de Anulación, 16 de abril de 2009, pár. 61. 
limitarian la noción de inversión y, en esa medida, los asuntos susceptibles de ser resueltos mediante arbitraje CIADI.

En efecto, en Phoenix c. República Checa, el tribunal se declaró falto de jurisdicción, afirmando que la adquisición de dos empresas checas por la demandante no constituía una inversión bajo el tratado suscrito entre Israel y la República Checa, ni bajo el Convenio CIADI. ${ }^{42}$ Teniendo en cuenta el acervo probatorio y la conducta de la demandante, el tribunal aseveró: “...[e]l Tribunal ha concluido que el inicio e intento de este arbitraje es un abuso del régimen de protección internacional de inversiones bajo el TBI $y$, consecuentemente, del Convenio CIADI..."+3.

En el caso bajo consideración, los árbitros comenzaron por reconocer que la determinación de su jurisdicción requería examinar tanto la definición de inversión provista por el Convenio CIADI, como la contenida en el TBI. ${ }^{4}$ Asimismo, explicaron que la interpretación de ambos instrumentos se encuentra regida por el derecho internacional, incluyendo las reglas de interpretación de la Convención de Viena de 1969 y los principios generales del derecho internacional. ${ }^{45}$

Luego de analizar la hisıria de la elaboración del Convenio ClADl en detalie y el Informe de los Directores Ejecutivos del Banco, el Comité ad hoc consideró que “...el hecho de que el Arbitro Único dejara de considerar, por no mencionar su aplicación. Ia definición de inversión provista por el Acucrio [cs] un grase crror que dio lugar a una falta manificsta al cjercicio de jurisdiccionn...". Finalmente, concluyó: "...la causal de amulación establecida en el articulo $52(1)$ (b) del Comenio CIADI especifica que 'el Tribunal ha excedido manifiestamente sus poderes'. Se concluye que el Tribunal cxcedio sus poderes al dejar de ejercer la jurisdiccioin con que fue dotado por los términos del Actucrio y la Comvención, y que lo hizo de manera 'maniffesta' ...". Traducción libre. Malaysian Historical Salvors SDN BHD c. Malasia, Caso CIADI No. ARB/05/10, Decisión sobre Solicitud de Anulación, 16 de abril de 2009, par. 74 \& 80 . Así pues, en el caso anterior se reconoce una importancia particular a la definición de inversión contenida el tratado de inversión, más alłá de la noción que pudiere construirse en el marco del Convenio CIADI.

42. Phoenix Action, Lul. c. Repuiblica Checa, Caso CIADI No. ARB/06/5, Laudo, 15 de abril 2009, pár. $121-122$.

43. Traducción libre. Phoenix Action, Ltd. c. Repüblica Checa, Caso CIADI No. ARB/06/5, Laudo, is de abril 2009, pár. 151.

44. Phoenix Action. Lid. c. Repuiblica Checa, Caso CIADI No. ARB/06/5, Laudo, 15 de abril 2009, pár. 73, ss.

45. Phoenix Action, Lud. c. Ceech Republic, Caso ClADl No. ARB/06/5, Laudo, 15 de abril 2009, pár. 75.

152 Revista Ecuatoriana de Arbitraje 
Basándose en este análisis inicial, el tribunal pasó a estudiar el concepto de inversión bajo el Convenio CIADI. Al respecto, recordó que la ausencia de una definición de 'inversión' en dicho instrumento, hace necesario recurrir a los criterios desarrollados por la jurisprudencia en el pasado. En ese orden de ideas, recurrió al 'Test Salini', para determinar si en efecto existía una inversión. Sin embargo, al entrar a considerar el cuarto criterio (contribución al desarrollo del estado receptor), el tribunal se manifestó a favor de adoptar un enfoque menos ambicioso, reduciendo el requisito a la presencia de una contribución a la economía del Estado receptor. ${ }^{46}$

Posteriormente, los árbitros buscaron una interpretación adecuada de 'inversión' para el contexto del Convenio CIADI y del TBI, a la a luz de los principios del derecho internacional. Sobre esta base, se determinó que el propósito del mecanismo de protección internacional de inversiones no era salvaguardar actividades contrarias a las leyes del Estado receptor o realizadas de mala fe. Es así como el Tribunal de Phoenix agregó dos criterios adicionales a aquellos enunciados en Salini c. Marruecos, a saber: (i) que la inversión se realice de conformidad con las normas del Estado receptor, y (ii) que la inversión sea bona fide. ${ }^{77}$

Respecto del primero, los árbitros concluyeron que, aun cuando el tratado de inversión no condicione la protección de la inversión a su conformidad con el derecho nacional de manera explícita, este requisito se encuentra implícito; así, las protecciones otorgadas a la inversión se pierden cuando ésta ha sido efectuada de manera contraria a las leyes del Estado receptor. En tal caso, el tribunal podrá declararse falto de jurisdicción. ${ }^{48}$

\footnotetext{
46. Phoenix Action, Lud. c. Czech Republic, Caso CIADI No. ARB/06/5, Laudo, 15 de abril 2009, par. 85 \& 93-95.

47. Esta conclusión es resumida explicitamente por el propio tribunal, Véase: Phoenix Action, Ltd, c. República Checa, Caso CIADI No. ARB/06/5, Laudo, 15 de abril 2009, pár. 114.

48. Phoenix Action, Lut. c. Repuiblica Checa, Caso CLADI No. ARB 06/5, Laudo, 15 de abril 2009, pár. 104.
} 
En cuanto al criterio adicional de buena fe, el tribunal manifestó que las partes "... deben actuar de manera honesta y justa entre ellas, representar sus motivos e intenciones sinceramente, y abstenerse de tomar ventaja injustamente...".49 Se explicó que la precitada regla había sido reconocida en el pasado en otros casos CIADI; particularmente, la decisión se fundamentó en los casos Inceysa c. El Salvador y Plama c. Bulgaria. ${ }^{50}$ El tribunal de Phoenix resaltó que su tarea era prevenir un abuso del sistema de protección de inversiones bajo el Convenio CIADI, asegurando el cumplimento del principio de buena fe por las partes. ${ }^{51}$

A partir de los casos anteriores, se puede apreciar cómo los criterios jurisprudenciales, incluyendo el conjunto de condiciones ampliado de Salini, pueden así actuar como limitantes de la materia arbitrable. Particularmente, las condiciones introducidas por el tribunal del caso Phoenix resultan relevantes para la formulación de objeciones a la jurisdicción del tribunal bajo argumentos de ilegalidad, fraude y corrupción.

Por otra parte, existe controversia sobre la existencia de una única noción de inversión aplicable en el sistema CIADI y fuera de él, como sería el caso de los arbitrajes de inversión bajo las reglas de la CNUDMI o la CCI. De acuerdo con algún sector de la doctrina, en tales arbitrajes no parece necesario construir una noción de inversión más allá de la provista por el tratado. Así, una disputa que no sería arbitrable ante un tribunal CIADI podría llegar a serlo ante un tribunal CNUDMI o CCI. ${ }^{52}$

Pues bien, el tribunal del caso Romak c. Uzbekistán, se pronunció recientemente en contra de esta posición, señalando que:

49. Traducción libre. Phoenix Action, Ldd. c. Repuihlica Checa, Caso CIADI No. ARB/06/5, Laudo, 15 de abril 2009, pár. 107.

50. Véase, Phoenix Action. Lud. c. Repíhlica Checa, Caso CIADI No. ARB/06/5, Laudo, 15 de abril 2009. pár. 112

51. Phoenix Acrion. Lud. c. Repuiblica Checa, Caso ClADI No. ARB/06/5, Laudo, 15 de abril 2009, pár. 106-113.

52. Véase, por ejemplo, DUGAN, Christopher, et. al, Imvestor - State Arhitration, Oxford University Press, 2008, p. 259. 
"Romak ha sugerido que la definición del término "inversión" puede variar dependiendo de la elección entre arbitraje UNCITRAL o CIADI por parte del inversionista; también ha sugerido que la definición de "inversión" en procedimientos UNCITRAL (es decir, bajo el TBI solo) es más amplia que en el arbitraje CIADI. El tribunal arbitral no comparte esta opinión, que podría llevar a resultados "irrazonables". Esta perspectiva implicaría que la protección sustantiva ofrecida por el TBI sería restringida o ampliada, según sea el caso, meramente en virtud de una elección entre los diversos mecanismos de resolución de disputas previstos por el tratado. Esto sería tanto absurdo como irrazonable. Naturalmente, existen restricciones jurisdiccionales específicas, impuestas por el Convenio CIADI, como por ejemplo la limitación respecto de personas naturales que tienen doble nacionalidad o a la existencia de una "diferencia de naturaleza jurídica". Empero, dichas restricciones no afectan la definición de "inversión". 53

Aceptar que la noción de inversión varía de acuerdo con las reglas de procedimiento aplicables ${ }^{5+}$ también supondría afirmar que las cuestiones de arbitrabilidad se encontrarían sujetas a dichas reglas.

\subsubsection{CONDICIONES Adicionales}

Además de la definición misma de inversión, los TBIs incluyen condiciones adicionales para que una inversión sea considerada como tal bajo el tratado. Con la proliferación de casos relacionados con ilegalidad, fraude y corrupción, estas condiciones -que incluyen la exigencia de respeto a las leyes del estado

53. Traducción libre. Romak S.A. c. Repuiblica de Ushekistán, Laudo UNCITRAL, 26 de noviembre de 2009, par. 193-194.

54. En relación con esta discusión, véase: SILVA-ROMERO, Eduardo, "Por un regreso al senticlo ordinario de la palabra "inversión"”, cn: Revista Ecuatoriana de Arbitrajc, 2009, p. 227: "Es ain más absurto que se sostenga, cxplicita o implicitamente, que la nociön de 'inversión' depende del mecanismo de resoltucion de litigios previsto en el TBI escogido por el inversionisfa. No parece, en efec10. lógico que una misma operación económica realizada, por cjemplo. en territorio ectutoriano pueda ser calificada de 'inversion' por un tribunal CNUDMI y no lo sea por un tribunal arbitral CIADI." 
receptor- vienen siendo consideradas más frecuentemente por los Estados como parte integral de los acuerdos internacionales por ellos celebrados. A continuación se analizarán estas condiciones.

\section{Observancia de las leyes del Estado receptor}

En ocasiones, la legalidad de la inversión es una condición adicional para su protección, en razón de una disposición del tratado de inversión aplicable, cuya estipulación no resulta inusual hoy en día. ${ }^{55}$

Por ejemplo, en el caso Fraport c. Filipinas, el Estado demandado alegó que el tribunal carecía de jurisdicción, en cuanto la inversión del demandante había sido realizada en violación de las leyes de Filipinas. ${ }^{56}$ Esta circunstancia parecía especialmente relevante en sede de jurisdicción, dado que el artículo 1 (1) del TBI entre Filipinas y Alemania dispone que "[e]l término inversión significa cualquier clase de activo aceptado de acuerdo con las leyes y regulaciones respectivas de cualquiera de los Estados contratantes..." ${ }^{57}$.

Como fundamento de estas aseveraciones, el Estado alegó que Fraport había infringido la legislación de control y posesión extranjera -la llamada "Ley Anti Dummy" (ADL, por sus siglas en inglés), que impone ciertos límites a los extranjeros para intervenir en la dirección, administración, control u operación de una compañía de utilidad pública. Asimismo, según Filipinas, el

55. Son varios los laudos relacionados con tratados que exigian la conformidad de la inversión con las leyes del Estado receptor. Por ejemplo, véase: Tokios Tokeles ve Ucrania, Caso CIADI No. ARB/02/18, Decisión sobre Jurisulicción, 29 de abril de 2004, pr. 17: Salini Costruttori Spd \& Anor c. Reino de Afarrucens, Caso CIADI No ARB/00/4, Laudo de Jurisdicción, 23 de julio de 200I, par. 45, Saipem S.p.A. c. Republica Popular de Bangladesh, Caso CIADI No. ARB/05/7, Decisión, 21 de marzo de 2007, par. 79, ss.

56. Fraport AG Frankfurt Airport Services Worldwide c. Repuiblica de Filipinas, Casa CIADI No. $\mathrm{ARB}(03 / 25,16$ de agosto de 2007, pár. 4.

57. Traducciön libre. Fraport AG Frankfurt tirport Senvices INowldwide c. Repuiblica de Filipinas, Caso CIADI No. ARB/03/25, 16 de agosto de 2007, pír. 281. 
inversionista buscó -mediante sistemas corporativos y un acuerdo secreto entre los accionistas- evadir el requisito constitucional que exige que la participación extranjera en una empresa de utilidad pública no exceda el $40 \%$ del capital. ${ }^{58}$ Por su parte, Fraport discutió los hechos y alegó que, en cualquier caso:

"[D]el objeto y propósito del TBI se deriva que la frase "de acuerdo con las leyes" no significa que las inversiones extranjeras deben cumplir con todos y cada una de las disposiciones del derecho doméstico, so pena de correr el riesgo de perder la protección otorgada por el TBI... Sería en efecto inapropiado e inconsistente con el TBI, privar al inversionista de las protecciones del TBI sobre la base de la infracción al derecho doméstico donde, por ejemplo, tal incumplimiento puede ser saneado o rectificado por el inversionista..." ${ }^{159}$.

El análisis del Tribunal comenzó por señalar que:

“...[L]as fronteras de la jurisdicción de este Tribunal están delimitadas por el pacto arbitral, en este caso, tanto el TBI como la Convención de Washington. El artículo 25 de la Convención de Washington, que dispone, inter alia, parámetros de jurisdicción ratione materiae, no define 'inversión', dejando a las partes que incorporan la jurisdicción CIADI la tarea de proveer una definición, si así lo desean. En tratados bilaterales de inversión que incorporan una opción de arbitraje CIADI, la palabra 'inversión' es un término técnico, cuyo contenido en cada instancia debe ser determinado por el lenguaje del TBI pertinente, que sirve como lex specialis respecto del artículo 25 de la Convención de Washington." 60

El Tribunal examinó los estándares legales aplicables a esta limitación ratione materine a su jurisdicción. En ese sentido, entró a considerar la voluntad del Estado receptor al ratificar el trata-

58. Fraport AG Frankfurt Airport Sentices Horlduide c. Republica de Filipinas, Caso CIADI No. ARB/03/25, 16 de agosto de 2007, pair. 120 \& 285-291.

59. Traducción libre. Fraport AG Frankfurt Airport Services Horlduide c. Repuiblica de Filipinas, Caso CIADI No. ARB 03/25, 16 de ugosto de 2007, pár. 304.

60. Traducción libre, Fraport AG Frankfurt Airport Senvices Worlduide c. Repuiblica de Filipinas, Caso CIADI No. ARB $03 / 25,16$ de agosto de 2007, pảr. 305. 
do de inversión, observando que "...el tratado de inversión explícita y reiteradamente requería que una inversión, a fin de poder ser protegida por el tratado, tendría que cumplir con la ley del Estado receptor...". ${ }^{61}$ Finalmente, concluyó que "el cumplimiento de las leyes del Estado receptor es una condición explicita y dificilmente irrazonable en el Tratado y su Protocolo anexo".62

Este caso sugiere que, cuando un tratado condiciona la protección de una inversión a que ésta haya sido realizada de conformidad con las leyes del estado receptor, establece una restricción material a la jurisdicción del tribunal. En este contexto surge un nuevo interrogante, a saber, ¿qué ocurre cuando el acto de ilegalidad no se presenta en el momento en que se realizó la inversión, sino que deviene durante el desarrollo de la actividad de que se trate?

Nuevamente es el caso Fraport el llamado a ocupar un lugar central en nuestra reflexión. En efecto, en dicho caso Filipinas alegaba que la inversión objeto de la controversia no había sido aceptada conforme a sus leyes, añadiendo que "...inclusive después de haber sido 'admitida', una inversión puede estar fuera del campo de aplicación de las protecciones del TBI, cuando sea implementada de una manera materialmente contraria a las leyes del Estado receptor que regulen la inversión o las actividades de inversión... ${ }^{63}$ En tal caso, según el Estado demandado, se vería afectada la jurisdicción del tribunal. ${ }^{64}$ Frente a esta posición, los árbitros determinaron que

“...si, al tiempo de iniciación de la inversión, se ha cumplido con el derecho del Estado receptor, los alegatos del Estado sobre violaciones de su derecho en el curso de la inversión,

61. Traducción libre. Fraport AG Frankfurt dirport Services Worldwide c. Repuiblica de Filipinas, Caso CIADI No. ARB/03/25, 16 de agosto de 2007, pár. 398.

62. Traducción libre. Fraport AG Frankfurt Airport Services Worldwide c. Repuiblica de Filipinas, Caso CIADI No. ARB/03/25, 16 de agosto de 2007, pár. 404.

63. Traducción libre. Fraport AG Frankfurt dirport Sentices Worldwide c. Repriblica de Filipinas, Caso CIADI No. ARB/03/25, 16 de agosto de 2007, pár. 286.

64. Fraport AG Frankfiurt Airport Senices Worldwide c. Repuiblica de Filipinas, Caso CIADI No. ARB/03/25, 16 de agosto de 2007, pár. 344 - 345. 
como justificación de acciones estatales respecto de la misma, pueden ser una defensa frente a las pretensiones [acerca de] las violaciones sustantivas del TBI, pero no podrían privar a un tribunal, que actúa bajo la autoridad [conferida] por el TBI, de su jurisdicción". ${ }^{\prime 6}$

En este evento, la ilegalidad no actuaría como una limitación objetiva de la materia arbitrable sino que entraría a afectar la valoración del mérito de las pretensiones del inversionista.

En el caso de Fraport, el tribunal declinó su jurisdicción, considerando así que la objeción de ilegalidad se constituía en una causal de inarbitrabilidad de la disputa.

\section{Limites del consentimiento del Estado al arbitraje de inversión}

Las cuestiones de ilegalidad también han sido vinculadas con el alcance del consentimiento otorgado por el Estado para llevar una disputa de inversión a arbitraje. Así, el Estado podría defenderse argumentando que su consentimiento se restringe a aquellas disputas que se refieren al tipo de inversión definido por el tratado. En esa medida, el argumento se confunde en sus efectos con el relativo a la definición de inversión: en ambos casos, la consecuencia final es sustraer ciertas disputas de aquellas susceptibles de ser sometidas a arbitraje, a partir de una delimitación del consentimiento el Estado, con base en la noción de inversión.

Por ejemplo, el tribunal CIADI del caso Inceysa c. República de El Salvador se declaró falto de jurisdicción para resolver la disputa relacionada con reclamos derivados del incumplimiento de un contrato por parte del Estado, al expropiar una empresa española arguyendo que la inversión de la demandante no había sido realizada de conformidad con la ley salvadoreña.

65. Traducción libre. Fraport AG Frankfurt Airport Senices Norldwide c. Republica de Filipinas, Caso CIADI No. ARB/03/25, 16 de agosto de 2007, pár. 345. 
El Salvador alegó que el tribunal carecía de jurisdicción, ya que su consentimiento no contemplaba la protección de "...inversiones tales como las basadas en contratos para proveer servicios al Estado, que hubieren sido obtenidas mediante fraude, falsificación y corrupción..." "...las inversiones hechas de acuerdo con la legislación salvadoreña... ". ${ }^{67}$

El tribunal comenzó su análisis definiendo su jurisdicción de conformidad con el Artículo 41 del Convenio CIADI ${ }^{68}$, añadiendo más adelante -en relación con la inversión de Inceysaque "...al constituir la legalidad de dicha inversión un presupuesto para que este Tribunal pueda ser competente, la determinación de la citada legalidad [de la inversión] solo puede ser hecha por el tribunal de la causa, es decir, por este Tribunal de Arbitraje" ${ }^{69}$

El tribunal observó que, al abordar el tema de la legalidad de la inversión en una etapa temprana del proceso, única y exclusivamente buscaba resolver sobre su competencia. ${ }^{70}$

El tribunal comenzó por revisar el tema del consentimiento de la demandante, a partir del Artículo 25(1) del Convenio CIADI. Los árbitros discreparon con el argumento planteado por la demandante, consistente en que el consentimiento de El Salvador para el arbitraje CLADI fue otorgado al momento de suscribir y ratificar el acuerdo y no puede estar sujeto a limitación alguna, de manera tal que cualquier limitación del mismo constituiría un retiro unilateral del consentimiento contrario al artículo 25(1) del instrumento. ${ }^{71}$ En ese orden de ideas, concluyó el tribunal:

66. Inceysa Vallisoletana S.L. c. República de El Salvador, Caso CIADI No. ARB/04/26, Laudo, 2 de agosto de 2006, pár. 45.

67. Inceysa Vallisoletana SL. c. Repuiblica de El Salvador, Caso CIADI No. ARB/04/26, Laudo, 2 de agosto de 2006, pár. 141.

68. Incessa Vallisoletana S.L. c. República de El Salvador, Caso CIADI No. ARB/04/26, Laưo, 2 de agosto de 2006, pár. 148, ss.

69. Inceysa Vallisoletana S.L. c. Repuiblica de El Salvador, Caso ClADI No. ARB/04/26, Laudo, 2 de agosto de 2006, pár. 209.

70. Inceysa Vallisoletana S.L. c. Republica de El Sahrador. Caso CIADI No, ARB/04/26, Laudo, 2 de agosto de 2006, pár. 213. 
“...[E]l análisis del contenido y los alcances del consentimiento de las partes signatarias de un acuerdo de protección recíproca a las inversiones no puede ser visto como la imposición de limitaciones a dicho consentimiento. Por el contrario, es un ejercicio obligatorio que debe efectuar todo Tribunal de Arbitraje, con el objeto de resolver si la controversia que se le plantea está sometida o no a su competencia, de acuerdo con el contenido real del consentimiento manifestado por las partes". ${ }^{72}$

Más adelante, encontró que la exclusión de inversiones que contravienen las leyes locales era expresión de la intención de España y El Salvador, al suscribir el tratado de inversión; esta conclusión se sustentó en el texto del tratado y en los travaux préparatoires. ${ }^{73}$

Es así como el Tribunal sostuvo que el comportamiento fraudulento de la demandada constituía una infracción a la legislación nacional, que impedía a la inversión gozar de las protecciones del TBI y restringía la posibilidad del tribunal de pronunciarse sobre el tema. ${ }^{74}$

Un ejemplo similar puede encontrarse en el caso Rumeli Telekom A.S. y Telsim Mobil Telekomikasyon Hizmetleri AS c. República de Kazakstán, donde el Estado demandado alegó que no

71. Inceysa Vallisoletana S.L. c. Repuiblica de El Salvador, Caso CIADI No. ARB/04/26, Laudo, 2 de agosto de 2006, pair. 171.

72. Inceysa Vallisoletana S.L. c. Repuiblica de El Salvador; Caso CIADI No. ARB/04/26, Laudo, 2 de agosto de 2006, pár. 172.

73. Inceysa Vallisoletana S.L. c. Repuiblica de El Salvador, Caso CIADI No. ARB/04/26, Laudo, 2 de agosto de 2006, pár. 190, ss.

74. En ese sentido, afirmo el tribunal: "En la controversia que ocupa a este Tribunal de Arbitraje, existen hechos y razones claras que configuran el supuesto antes indicado, puesto que Inceysa actuó de manera inpropia para que se le adjudicara la licitacion que hizo posible su inversión y, por ende, no puede concedérsele la protección que el APPRI otorga ... La clara y contundente evidencia de las violaciones cometidas por Inceysa durante el proceso de la licitacion. lleva a este Tribunal a resolver que la inversión de Incersa no pucte, bajo ninguna circunstancia, gozar de la protección del APPRI. Permitir que Inceysa se heneficiara de la realizacion de ana inversión claramente violatoria de los fundamentos de la licitación en que se arigino, seria una falta grave a la justicia que este Tribunal esta obligado a impartir. Ninguin sistema juridico sustentado en bases racionales permite que se bencficie quien ha realizado una cadena de actos claramente ilegales" Inceysa Vallisoletana S.L. c. Repuiblica de El Salvador, Caso CIADI No. ARB/04/26, Laudo, 2 de agosto de 2006, pár. 244. 
había consentido a la jurisdicción CIADI sobre la disputa, entre otros, porque las inversiones del demandante no eran legales e infringían los principios de buena fe, nemo auditur propiam turpitudinem allegans y el orden público internacional. ${ }^{75}$ El tribunal comenzó por analizar el artículo 25 del Convenio CIADI, ${ }^{76}$ abordando posteriormente el TBI concluido entre la República de Turquía y la República de Kazakstán del 1 de mayo de $1992 .{ }^{77}$ Sobre esta base, afirmó:

"...[P]ara recibir la protección de un tratado bilateral de inversiones, las inversiones objeto de la controversia deben ser conformes con las leyes y regulaciones del Estado receptor. De otro lado... las inversiones en el Estado receptor sólo se excluirán de la protección del tratado si han sido realizadas en violación de los principios jurídicos fundamentales del Estado receptor. Tras un examen cuidadoso de las pretensiones del demandado, el Tribunal Arbitral ha llegado a la conclusión de que el demandado no probó que la inversión de los demandantes habría sido fraudulenta o violatoria de alguna ley o regulación de Kazakstán...". ${ }^{78}$

El Estado intentó posteriormente la declaratoria de nulidad del laudo, alegando, entre otros, "...que el Tribunal manifiestamente excedió sus poderes al encontrar que tenia jurisdicción, cuando carecín de ella, en razón de la ilegalidad de la inversión."79 El Comité ad hoc encontró que el laudo no había excedido manifiestamente sus facultades, ya que "...no dejó de dar razones para [justificar] su decisión de que las inversiones de Rumeli y Telsim no violaban el derecho internacional o las leyes de Kazakstán" ${ }^{80}$ Por este y otros motivos, el Comité rechazó la solicitud formulada por el demandado.

75. Rumeli Tclekom d.S \& Telsim Mobil Telckomikusyen Hizmetleri A.S. v: Kuzakhstau, Caso CIADI No. ARB/05/16, Laudo, 29 de julio de 2008, par. 310.

76. Rumeli Telckom AS. \& Telsim Mobil Telckomikasyon Hizmetleri d.S. vi Kuzakistum, Caso CIADI No. ARB/05/16, Laudo, 29 de julio de 2008, pár. 312, ss.

77. Rumeli Telckom A.S. \& Telsim Mohil Telekomikasyon Hiemelleri A.S. v: Nazakhstan, Caso CIADI No. ARB/05/16, Laudo, 29 de julio de 2008, paic. 315.

78. Rumeli Telekom a S \& Teisim Mobil Teickomikasyon Hizmetleri d.S. u: Kazakisisum, Caso CIADI No. ARB/05/16, Laudo, 29 de julio de 2008, pair. 319-320.

79. Rumeli Telekom A S. \& Telsim Mobil Telckomikasyon Hizmetleri A.S. I: Kazaklistan, Caso CIAD1 No. ARB/05/16, Decisión del Comité Ad Hoc, 25 de marzo de 2010, pàr. 3.

80. Rumeli Telekom A S \& Telsim Mohil Telekomikusyon Hizmetleri A S. v: Kazakhstan, Caso CIADI No. ARB/05/16. Decisión del Comitć Ad Hoc, 25 de marzo de 2010, par. 99. 
Nótese que, en los dos casos citados, se reconoció la posibilidad de que la ilegalidad de la inversión tenga el efecto de privar al tribunal de jurisdicción en relación con el consentimiento otorgado por los Estados para arbitrar ciertas disputas. Lo anterior supone que la jurisprudencia ha reconocido a la ilegalidad el efecto de sustraer ciertas materias de la posibilidad de ser resueltas por los árbitros, apareciendo así una causal de inarbitrabilidad ratione materiae.

Ahora bien, además de las restricciones a la arbitrabilidad por cuestiones de ilegalidad, algunos tratados incluyen otro tipo de requisitos, que igualmente condicionan la arbitrabilidad de la disputa. Aunque sin relacionarse directamente con el tema de la ilegalidad, resulta interesante la existencia de otro tipo de condiciones que pueden afectar el consentimiento del Estado sobre la materia arbitrable, en el marco de un arbitraje de inversión. Entre estas limitaciones, cabe señalar la relacionada con la exigencia de permisos o autorizaciones especiales para la inversión y la exclusión de ciertos sectores económicos de la protección del tratado.

Por ejemplo, antes de denunciar el Convenio CIADI en el año 2009, Ecuador envión una notificación al CIADI excluyendo de la jurisdicción del Centro "las diferencias que surjan en materias relativas al tratamiento de una inversión, que se deriven de actividades económicas relativas al tratamiento de una inversión que deriven de actividades económicas relativas al aprovechamiento de recursos naturales como petróleo, gas, minerales u otros" ${ }^{81}$ Asimismo, existen tratados que impiden considerar como 'inversión extranjera' actividades relacionadas con algunos sectores económicos. ${ }^{82}$

81. Véase: Embajada del Ecuador, Nota No, 4-3-74/07, Washington, 4 de diciembre de 2007 [en linea] http://icsid worldbank org/ICSID/CSID/ViewNewsRcleases.jsp.

82. En ese sentido, el TLC Chile-Colombia, dice en su articulo 9.1.4: "[c]ste Capitulo no se aplica a las medidas que adopte o mantenga una Parte en cuanto a los inversionistas de la otra Parte y a las inversiones de dichos inversionistas, en instituciones financieras del territorio de la Parte". Asimismo, el artículo $9.14 \mathrm{del}$ mismo instrumento dispone: "[n]ada de lo dispuesto en este Capitulo se interpretará como impedimento para que una Parte adopte, mantenga o haga cumplir cualquier medida, por lo demás compatible con este Capitulo, que considere apropiada para garantizar que las actividades de inversión en su territorio se efectúen tomando en cuenta la legislación metio ambiental en esa Parte". TLC Chile-Colombia, 8 de mayo de 2009 [fecha de entrada en vigencia], arts. 9.1.4 \& 9.14. 
En este caso, aún si la inversión fuera tal desde el punto de vista de la definición relevante y cumpliera con la legislación del Estado receptor, las cuestiones relacionadas con ésta no serian susceptibles de ser resueltas mediante arbitraje.

A manera de conclusión de este apartado, es importante señalar que el efecto de la inarbitrabilidad relacionada con cuestiones de ilegalidad, $y$ aún con las condiciones adicionales que acaban de señalarse, tendría como efecto la falta de jurisdicción del tribunal. Esta ausencia de jurisdicción operaría igualmente en caso de que la disputa fuese llevada ante una corte nacional, como bien lo permiten la mayoría de tratados relevantes. En efecto, las cortes no tendrían en este evento una jurisdicción general para conocer las cuestiones relativas al instrumento internacional, sino que sus facultades se verían restringidas por los mismos factores que limitan la jurisdicción del tribunal arbitral, y que se encuentran en el tratado y en la definición misma de inversión.

\subsubsection{Anulación y ejecutabilidad}

Ahora bien, el esfuerzo por encuadrar las objeciones relacionadas con los alegatos de ilegalidad, fraude y corrupción como cuestiones de arbitrabilidad, tiene como aplicación práctica la posibilidad de que éstas sean utilizadas como causales de anulación del laudo o para denegar su reconocimiento y ejecución (fuera del sistema del Convenio CIADI).

Como se señaló anteriormente, los laudos que no son emitidos por un tribunal que actúe bajo el Convenio CIADI, están sujetos a los recursos de anulación previstos por la legislación de la sede del arbitraje, dependiendo entonces su reconocimiento y ejecución de la Convención de Nueva York, siempre y cuando ésta haya sido ratificada por el Estado en cuyo territorio se ubica la sede arbitral. Tanto la Ley Modelo de la CNUDMI como la Convención de Nueva York enuncian la inarbitrabilidad de la 
disputa como causal denegación del reconocimiento y ejecución del laudo; por su parte, la Ley Modelo la contempla además como causal de anulación. ${ }^{83}$

En este sentido, arbitrar transacciones que no se encuentren cobijadas por la definición de 'inversión' aplicable o que no respeten los criterios jurisprudenciales desarrollados en torno a este concepto o que no cumplan con los requisitos adicionales exigidos por el tratado relevante, podría dar lugar a la interposición de un recurso de anulación contra el laudo o al rechazo de su reconocimiento y ejecución, en razón de la inarbitrabilidad del objeto de la controversia.

En este sentido, resulta fundamental para los inversionistas considerar esta posibilidad al momento de evaluar el sistema procesal escogido para el desarrollo del arbitraje. Discusiones como las que tuvieron lugar en el marco del proceso de anulación en los casos MHS c. Malasin y Patrick Mitchell c. Congo, no se circunscribirían a las causales particulares del Convenio CIADI sino que podrían también trasladarse en los términos aquí expuestos a ámbitos externos al CIADI.

Quedaría aún por resolver el interrogante sobre la ley aplicable para determinar las cuestiones de arbitrabilidad. En efecto, tanto la CNY como la Ley Modelo indican que la arbitrabilidad debe juzgarse en relación con la ley de la sede del arbitraje (en casos de anulación) o del sitio donde se solicita el reconocimiento y ejecución. En el caso del arbitraje de inversión, sin embargo, las restricciones a la arbitrabilidad vienen dadas en el tratado de inversión y en los principios de derecho internacional, dependiendo de la definición de inversión y de los criterios jurisprudenciales que se acojan. El rol de la ley de la sede del arbitraje queda así en entredicho.

83. Véase: Convención de Nueva York, 1958, articulo V.2.a; CNUDM1, Ley Modelo de Arbitraje Comercial Internacional, 1985, artículos 36.1.b.i. \& 34.2.b.i. 
Así las cosas, la aplicación del concepto de arbitrabilidad en el marco del arbitraje de inversión no está exenta de dificultades. Existirían al menos tres opciones frente al problema planteado. Primero, dejar sin aplicación las causales de anulación y de denegación de la ejecución del laudo de la Ley Modelo y de la $\mathrm{CNY}$ al no ceñirse estrictamente a las circunstancias para las que fueron previstas en el ámbito del arbitraje comercial. Segundo, aplicar dichas causales pero acogiendo una definición amplia de arbitrabilidad -como la que aquí se propone- y aceptando un cierto nivel de flexibilidad al interpretar la referencia a la ley de la sede del arbitraje, permitiendo que las cortes miren al texto del tratado y a los principios de derecho internacional donde se definen las restricciones ratione materine. ${ }^{84}$ Tercero, modificar dichos instrumentos para adaptarlos a los requerimientos del arbitraje de inversión, solución esta que, desde el punto de vista práctico, parece improbable.

\section{Conclusión}

Aunque ausente hasta el momento del ámbito del arbitraje de inversión, el concepto de arbitrabilidad parece entonces resultar de utilidad en dos momentos en relación con este tipo de arbitrajes. El primero, en la evaluación del impacto que los argumentos sobre ilegalidad y corrupción pueden tener sobre el desarrollo del arbitraje cuando la parte que los invoca es el Estado en defensa de la demanda presentada por el inversionista. Cómo se anotó, cuando es el inversionista el que alega estas circunstancias como una violación del tratado, los tribunales han

84. Ya en el àmbito de la CNY se ha adoptado una reconendación para guiar la aplicación del artículo II de la Convención, en consideración a los adelantos tecnológicos en materia de comunicaciones y a los avances legales y jurisprudenciales de ciertas jurisdicciones que resultan incompatibles con una interpretación estricta del texto de la Convención. Véase, CNUDMI, "Recomendación relativa a la interpretación del párrafo 2) del articulo It y del párrafo 1) del articulo VIl de la Convención de Nueva York, de 10 de junio de 1958, adoptada por la Comisión de las Naciones Unidas para el Derecho Mercantil Internacional el 7 de julio de 2006 en su $39^{\circ}$ periodo de sesiones", Ancxo II A/61 17, A/CN.9/WG.II/WP.139. De manera similar, podria barajarse la posibilidad de adoptar una recomendación para peccisar la particularidad del arbitraje de inversión en relación con la determinación de la ley apiicable en el contexto de los arbitrajes de inversión. 
entrado a tratar el tema sin cuestionar el alcance de su jurisdicción. El segundo, al momento de dilucidar la aplicación de la Convención de Nueva York y la Ley Modelo CNUDMI, en el caso de los laudos proferidos por fuera del sistema CIADI, en relación con las causales de anulación y denegación del reconocimiento y ejecución del laudo.

No es un secreto que el arbitraje de inversión se moldeó sobre el prototipo del arbitraje comercial internacional que, para el momento de la aparición del arbitraje de inversión, llevaba ya un largo camino recorrido y venía afianzándose poco a poco como la alternativa por excelencia para la resolución de controversias en el ámbito del comercio internacional.

Dada la diferencia generacional entre ambas instituciones, existe una fuerte tentación a trasponer de manera irreflexiva las instituciones jurídicas y los instrumentos que han impulsado el arbitraje comercial internacional en el campo del arbitraje de inversión. A pesar de la aparente similitud y de compartir un grupo de profesionales dedicados a la práctica en ambas áreas, resulta vital para el adecuado desarrollo del arbitraje de inversión poner de presente sus especificidades y hacerlas valer al momento de recurrir a los instrumentos que hasta el momento han permitido la consolidación del arbitraje comercial internacional. Este artículo espera contribuir con dicha reflexión. 